\title{
Article
}

\section{Entering Research: A Course That Creates Community and Structure for Beginning Undergraduate Researchers in the STEM Disciplines}

\author{
Nicholas Balster, Christine Pfund, Raelyn Rediske, and Janet Branchaw
}

University of Wisconsin-Madison, Madison, WI 53706

Submitted October 5, 2009; Revised December 30, 2009; Accepted January 12, 2010

Monitoring Editor: Julio F. Turrens

\begin{abstract}
Undergraduate research experiences have been shown to enhance the educational experience and retention of college students, especially those from underrepresented populations. However, many challenges still exist relative to building community among students navigating large institutions. We developed a novel course called Entering Research that creates a learning community to support beginning undergraduate researchers and is designed to parallel the Entering Mentoring course for graduate students, postdocs, and faculty serving as mentors of undergraduate researchers. The course serves as a model that can be easily adapted for use across the science, technology, engineering, and mathematics (STEM) disciplines using a readily available facilitator's manual. Course evaluations and rigorous assessment show that the Entering Research course helps students in many ways, including finding a mentor, understanding their place in a research community, and connecting their research to their course work in the biological and physical sciences. Students in the course reported statistically significant gains in their skills, knowledge, and confidence as researchers compared with a control group of students, who also were engaged in undergraduate research but not enrolled in this course. In addition, the faculty and staff members who served as facilitators of the Entering Research course described their experience as rewarding and one they would recommend to their colleagues.
\end{abstract}

\section{INTRODUCTION}

Working closely with an experienced researcher and engaging in the challenge and excitement of scientific discovery is often a transformative experience for undergraduate students (McGee and Keller, 2007). The benefits of undergraduate research experiences are numerous, well documented, and include increases in research skills, productivity, and preparation for postgraduate education (Kardash, 2000; Hathaway et al., 2002; Bauer and Bennett, 2003; Seymour et al., 2004; Hunter et al., 2007; Lopatto, 2007; Russell et al., 2007). Indeed, studies such as the Boyer Commission Report on Educating Undergraduates in the Research University and the Teagle Report from the American Society for Biochemistry and Molecular Biology (ASBMB) acknowledged the benefits of undergraduate research, and recommended research-based learning as the standard model for college

DOI: $10.1187 /$ cbe.09-10-0073

Address correspondence to: Janet Branchaw (branchaw@wisc.edu). education (Boyer Commission on Educating Undergraduates in the Research University, 1998; ASBMB, 2008). More recently, the National Academies Bio 2010 Report stated that, "All students should be encouraged to pursue independent research as early as is practical in their education" (National Research Council, 2003). As a result of these and other studies, numerous colleges, universities, and funding agencies have invested significantly in expanding undergraduate research opportunities (Boyd and Wesemann, 2009).

Although the benefits of undergraduate research experiences are well known, students still face many challenges when beginning research and often lack the support they need to ensure success. Such challenges include 1) learning how to identify and appropriately contact potential research mentors, 2) transitioning from the classroom to a learning environment built around a research community, and 3) learning how to integrate into the social structure of the research community. These challenges can be especially overwhelming for those from nonacademic backgrounds, who may not 
be familiar with the culture of research (e.g., first-generation college students), and for underrepresented minority students, who may feel isolated or intimidated by the behavioral norms of the research environment (Brown, 2006; Boyd and Wesemann, 2009). Importantly, undergraduate research experiences have been shown to be effective in recruiting and retaining these populations of students within the science, technology, engineering, and mathematics (STEM) disciplines, often leading to careers in research (Villarejo et al., 2008). Therefore, helping students overcome these challenges is important in our efforts to diversify the scientific research workforce.

In this article, we describe the development, implementation, and evaluation of a course for undergraduate students called Entering Research that focuses on helping students navigate the challenges of beginning research. This course provides a portal to research for undergraduate students, as well as a supportive community of peers and experienced researchers as course facilitators. Students who participate in the course are expected to attend class ( $1 \mathrm{~h} / \mathrm{wk})$ in addition to spending five to $15 \mathrm{~h}$ a week doing independent research with a mentor. In this 3-yr study (2006-2008), we first evaluated student self-assessment of their confidence, skills, and knowledge after completing one semester of Entering Research. In addition, we compared students taking this course with a control group also conducting undergraduate research, but not enrolled in Entering Research. Based on previous work, we assumed most students would benefit from conducting undergraduate research, but hypothesized that their experience would be enhanced by coupling this research experience with the supplemental course Entering Research. This enhancement would manifest itself in greater confidence, skills, and knowledge relative to when the students began the course and compared with a control group.

\section{Development and Implementation of the Entering Research Course}

Large, public research institutions such as the University of Wisconsin-Madison (UW-Madison) serve thousands of undergraduate students. Although campuses, like UW-Madison, typically offer a handful of undergraduate research programs that serve 100-200 students, a support structure with the capacity to serve all students does not exist. Consequently, the students who engage in undergraduate research tend to be those who are targeted by select programs, or those who already possess the confidence, skills, and knowledge they need to navigate a large research-focused university system on their own. The Entering Research course was developed to address these challenges and, through dissemination to individual departments, support a larger number of students to engage in research experiences.

The primary goals of the Entering Research course are to create a supportive learning environment to introduce students to the culture of research, to teach students valuable skills needed to become effective researchers, and to alleviate some of the work of faculty and lab personnel associated with mentoring novice student researchers. The course is designed to help students find a research mentor, explore the culture of research, write a research project proposal, and begin doing research. Students informally share their research experiences and learn about the diversity of experiences available through their peers. The "content" of the workshops comes from the students, and their engagement in the weekly, hour-long discussions is key. The course facilitator provides a framework for the discussions, relevant background reading materials, and structured assignments designed to help students develop positive relationships with their research mentors, define themselves as a member of the research community, and understand and communicate their research. The student learning objectives for the Entering Research course are presented in Figure 1 and the course outline is presented in Figure 2. Each semester consists of 14 1-h weekly sessions, for which students earn one credit. The course is taught in several small sections of five to 10 students each.

The Entering Research course was developed using an iterative approach of design, evaluation, and revision in partnership with 13 faculty/staff members and two postdoctoral fellows from 10 different biological and physical science departments across three colleges at UW-Madison. Summative student assessments coupled with facilitator feedback were used to develop a comprehensive facilitator's manual containing the instructional materials for course implementation, purposefully using a format that can be easily deconstructed and adapted for a range of settings (Branchaw et al., 2010).

In this study, we have focused on the first semester of the Entering Research course, which was taught every fall between 2006 and 2008 and enrolled 83 undergraduate students in total. The course has gained popularity with 55 students enrolled in fall 2009. The majority of participating students $(70 \%)$ were sophomores.

\section{METHODS}

At the beginning (pre) and end (post) of each fall semester (2006-2008), students enrolled in the Entering Research course completed an online survey aimed at assessing student satisfaction and learning outcomes. In addition, these students were asked to rank their confidence, skill, and knowledge as a researcher on a Likert scale, as well as respond to a series of open-ended questions. The surveys were modified from surveys used previously to evaluate undergraduate research experiences independently of this course (Handelsman et al., 2005; Pfund et al., 2006), and they included 14 questions pertaining to confidence, 14 questions pertaining to skill, and five questions pertaining to knowledge.

In addition, to determine the impact of the first semester of the Entering Research course, we used a "static-group" design (Fraenkel and Wallen, 2003). This design compared the students enrolled in the Entering Research course (also engaged in undergraduate research) with a group of similar undergraduate students (2008) who were not taking this supplemental course, but who were likewise required to conduct undergraduate research as part of an introductory biology course. The survey response rates for the Entering Research group and comparison group were $77 \%(64 / 83)$ and $39 \%(144 / 373)$, respectively. The respondents from the Entering Research group were 59\% female and 22\% were members of underrepresented ethnic groups. The 
Figure 1. The Entering Research course student learning objectives.

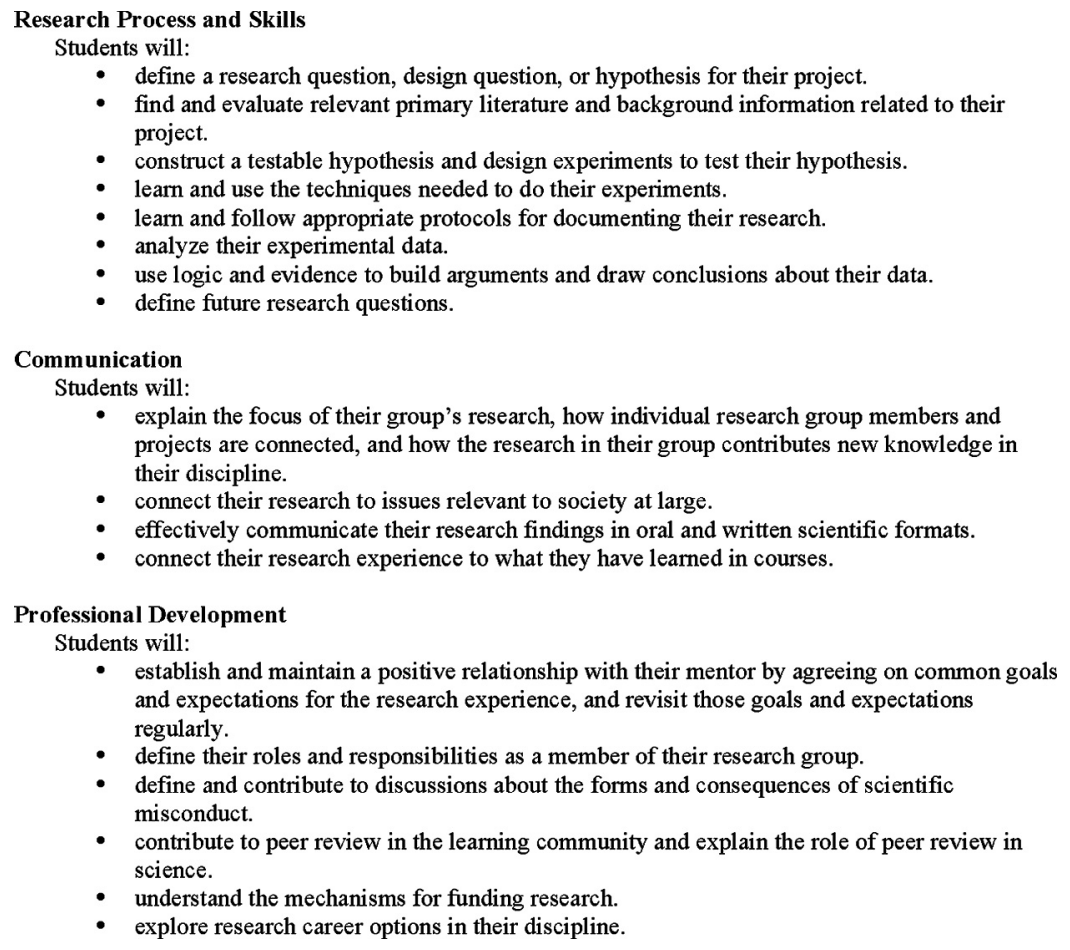

respondents from the introductory biology group were $60 \%$ female and $4 \%$ were members of underrepresented ethnic groups.

The same postsurvey was administered to both groups at the end of the semester. As articulated in Lapatto (2004), establishing a creditable control group is fraught with difficulties including the self-selective qualities of the institutions, personal motivations of the students themselves, and the variation in amount and intensity of one research experience to another. Because our study examined the effects of a supplemental course on undergraduate research and did not directly assess the undergraduate research experience itself, we avoided or were able to control for many of these confounding factors. The quantitative and qualitative responses from this comparison were combined and analyzed for reoccurring themes and significant differences.

Mean differences in the data from the Entering Research students who responded to both the pre- and postsurveys, as well as the comparisons with the control group, were each analyzed using two-way analyses of variance. Each question was analyzed as a main effect along with academic year. In addition, all interactions between year and question were assessed; if an interaction was significant, the main effects were interpreted relative to year. If interactions were not significant, each question was assessed (and reported) between pre- and postassessments or between students enrolled or not enrolled (relative to postassessment comparisons) in the Entering Research course. All effects were considered significant at $\infty=0.05$ by using SAS statistical software (SAS Institute, Cary, NC).

In addition to the quantitative analysis, students enrolled in the Entering Research course were asked to answer the following open-ended questions regarding their first-semester experience:

1. What aspects of this course have helped you most?

2. Has this course helped you navigate your lab experience? If so, how?

3. Have your views on science or research changed over the semester? If so, how?

We used a directed content analysis of these qualitative data to identify recurring themes (Hsieh and Shannon, 2005).

Lastly, the facilitators of the Entering Research course were surveyed at the end of each semester (2006-2008). Seven of the 15 facilitators were women and all were Caucasian. Facilitators were asked to rate the value of 10 different course components, the 14 topics discussed in the course, the course instructional materials including the facilitation materials (Branchaw et al., 2010), as well as the facilitation experience itself. This survey also was based on a survey used previously to evaluate facilitator experience (Pfund et al., 2006).

\section{RESULTS}

\section{Student Evaluation of the Entering Research Course}

Overall, postexperience course evaluations revealed that students valued the first semester of the Entering Research course, because they rated all of the topics covered in the course as helpful to their learning (Figure 3). Learning about ethics in research, small group discussions with their peers, and the process of developing a research project proposal were rated as most helpful among students. Students ranked 
Semester I - Fall

\begin{tabular}{|l|l|}
\hline Session & Topics \\
\hline $\begin{array}{l}\text { Session 0 } \\
\text { (Before start) }\end{array}$ & Finding a Research Mentor - no mig \\
\hline Session 1 & $\begin{array}{l}\text { Introduction to Entering Reseurch Part } \\
\text { I \& Finding a Research Experience }\end{array}$ \\
\hline Session 2 & The Nature of Science \\
\hline Session 3 & $\begin{array}{l}\text { Searching the Literature for Scientific } \\
\text { Articles }\end{array}$ \\
\hline Session 4 & $\begin{array}{l}\text { Reading Scientific Articles and } \\
\text { Mentoring Styles }\end{array}$ \\
\hline Session 5 & Your Research Group's Focus \\
\hline Session 6 & $\begin{array}{l}\text { Establishing Goals \& Expectations } \\
\text { with Your Mentor }\end{array}$ \\
\hline Session 7 & Who's Who in Your Research Group \\
\hline Session 8 & Documenting Your Research \\
\hline Session 9 & $\begin{array}{l}\text { Defining Your Hypothesis or Research } \\
\text { Question }\end{array}$ \\
\hline Session 10 & Designing Your Experiments \\
\hline Session 11 & Research Proposal Review Draft \#1 \\
\hline Final Research Proposal Presentations \\
\hline 13
\end{tabular}

Semester II - Spring

\begin{tabular}{|c|c|}
\hline Session & Topics \\
\hline Session 15 & $\begin{array}{l}\text { Introduction to Entering Research Part } \\
\text { II \& Science Communication }\end{array}$ \\
\hline Session 16 & $\begin{array}{l}\text { Research Project Outline \& Science } \\
\text { Abstract }\end{array}$ \\
\hline Session 17 & $\begin{array}{l}\text { Research Project Outline \& Science } \\
\text { Abstract continued }\end{array}$ \\
\hline Session 18 & Science \& Society \\
\hline Session 19 & $\begin{array}{l}\text { Peer Review of General Public } \\
\text { Abstracts }\end{array}$ \\
\hline Session 20 & Research Ethics \\
\hline Session 21 & $\begin{array}{l}\text { Making Effective Scientific } \\
\text { Presentations }\end{array}$ \\
\hline Session 22 & Research Careers \\
\hline Session 23 & Peer Review Draft \#1 Poster \\
\hline Session 24 & Outside Review Draft \#2 Poster \\
\hline Session 25 & Final Presentation Symposium \\
\hline Session 26 & $\begin{array}{l}\text { The Future of Y our Project - } \\
\text { Funding/Grants }\end{array}$ \\
\hline Session 27 & Peer Review of Mini-grant \\
\hline Session 28 & $\begin{array}{l}\text { Research Experience Reflections \& } \\
\text { Celebration }\end{array}$ \\
\hline
\end{tabular}

Figure 2. Entering Research course outline. Course outlines for both semesters are presented for reference. The beginning undergraduate research experience was investigated, so only data from semester I are reported in this paper. Instructional materials for both semesters are available in the Entering Research facilitator's manual (Branchaw et al., 2010).

web-based discussions and visiting peer laboratories lowest among the 20 survey questions regarding course satisfaction: no question received an average score of not helpful.

After the qualitative data were compiled and analyzed, five reoccurring themes were identified. Each theme is presented in Table 1, with the percentage of students who mentioned it, along with representative quotes from individual students.

\section{Student Self-Assessment of Confidence, Skill, and Knowledge as a Researcher}

Confidence, skill, and knowledge all significantly increased among students' self-ratings ( $p<0.001$; Figure 4$)$. The largest gains were seen in student knowledge at $22 \%$, followed by skills $(13 \%)$, and confidence $(10 \%)$. When questions in each category (confidence, skills, and knowledge) were examined individually, significant gains also were found. Within the confidence category, all but two areas of confidence were self-rated as significant gains among students $(p<0.01 ;$ Figure 5). The largest gains in confidence included writing a basic science proposal; identifying scientific misconduct; and interacting with their peers, with only one confidence gain rated below the "high" level. When gains in skill were assessed, all but two showed significant increases among students after completing the first semester of this course $(p<0.01$; Figure 6$)$. The largest gains in skill were general research skill and those related to their research project. Students' ability to work collaboratively and present scientific information did not change after the first semester of the course. Finally, significant gains were likewise reported by students relative to all five questions pertaining to their knowledge $(p<0.01$; Figure 7). Knowledge of what graduate school was like and knowledge related to the careers of science faculty showed the largest gains, although on average, all gains in knowledge jumped one rating level within the 5-point scale by the end of the first semester.

Given that the benefits of undergraduate research are well established (Seymour et al., 2004; Lopatto, 2007; Russell et al., 2007), the gains in confidence, skills, and knowledge reported by our students supported our assumption that most students would benefit from conducting undergraduate research and thus could be unrelated to participation in the Entering Research course. Therefore, we also tested whether the course had an impact beyond the research experience by examining a comparison group of students who participated in a semester-long independent research experience as part of a sophomore level introductory biology course. The ma- 
Figure 3. Student satisfaction with the Entering Research course. Each bar represents the mean and standard error of survey responses from students who took the first semester of Entering Research (2006-08; $\mathrm{n}=64)$. Students were asked to report how helpful each of the topics was to their learning about research on a scale of 1 through $4(1=$ Not Helpful; $2=$ Somewhat Helpful; 3 = Helpful; 4 = Very Helpful).

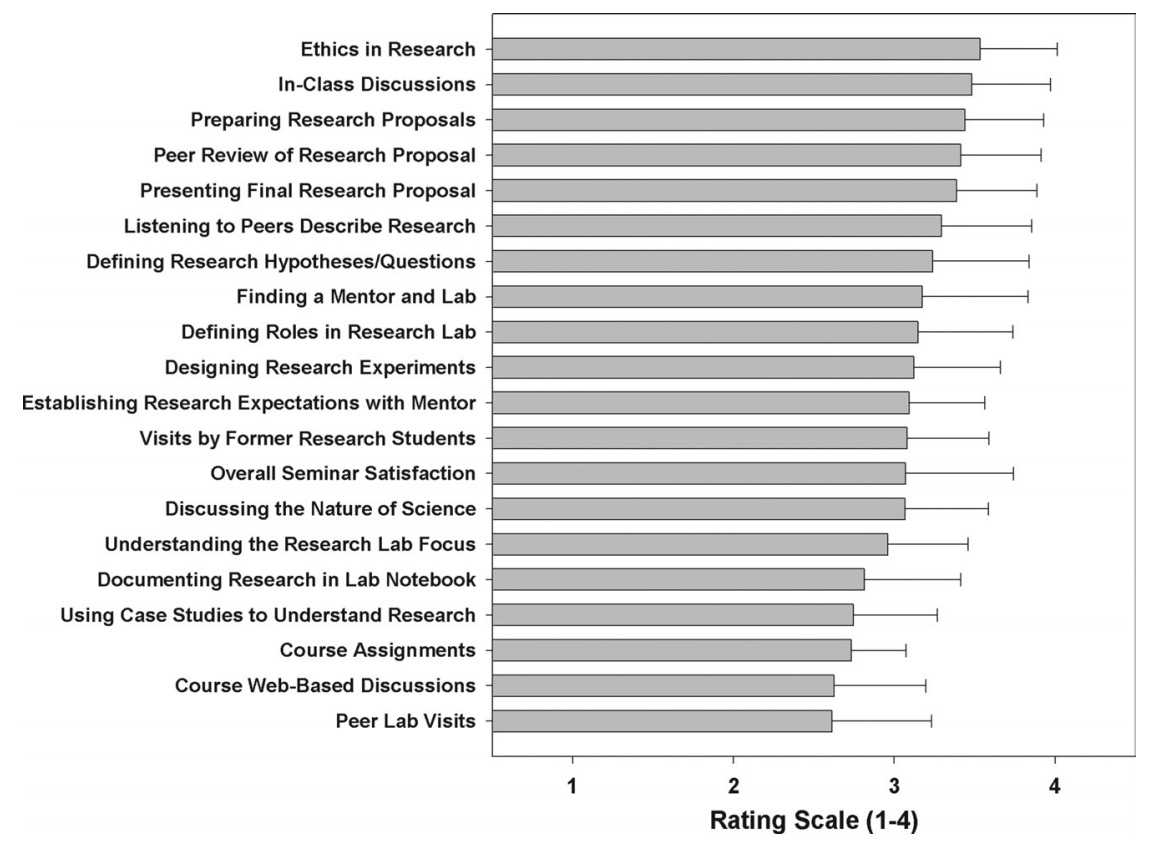

tion, students in the Entering Research course also reported significantly higher confidence in their ability to make connections between their research experience and their biology or physical sciences classroom experiences, in contrast with students engaged in undergraduate research as part of the introductory biology course $(p<0.01)$. Within the skills category, there were three areas of significant difference between the two groups: developing a research project, conducting a research project, and analyzing data $(p<0.05)$. The two knowledge questions that show significant differences between the two groups are those focused on what graduate school is like and the career paths of science faculty; the Entering Research students self-assessments were significantly greater than those of the introductory biology students in both these areas $(p<0.01)$.

\section{Facilitator Evaluation of the Entering Research Course}

Although the purpose of partnering with faculty and staff from across disciplines was to ensure integration of the course into a variety of academic settings, we learned through follow-up evaluations submitted by 14 of the 15 course facilitators that their participation in the course also served as a professional development opportunity. All respondent facilitators said they would facilitate the course again and that they would recommend this opportunity to a colleague. One facilitator noted the following:

"I enjoyed helping develop the course and the instructional team; I particularly like sharing ideas and processing our experience with the team on a weekly basis [at instructor meetings]. In addition, I liked being able to discuss issues and goals/expectations for research with this small group of undergrads. It was particularly rewarding to coach students when they were first trying to get into a lab. It was very clear 
Table 1. Student impressions from Entering Research course evaluations: coded themes and representative quotes

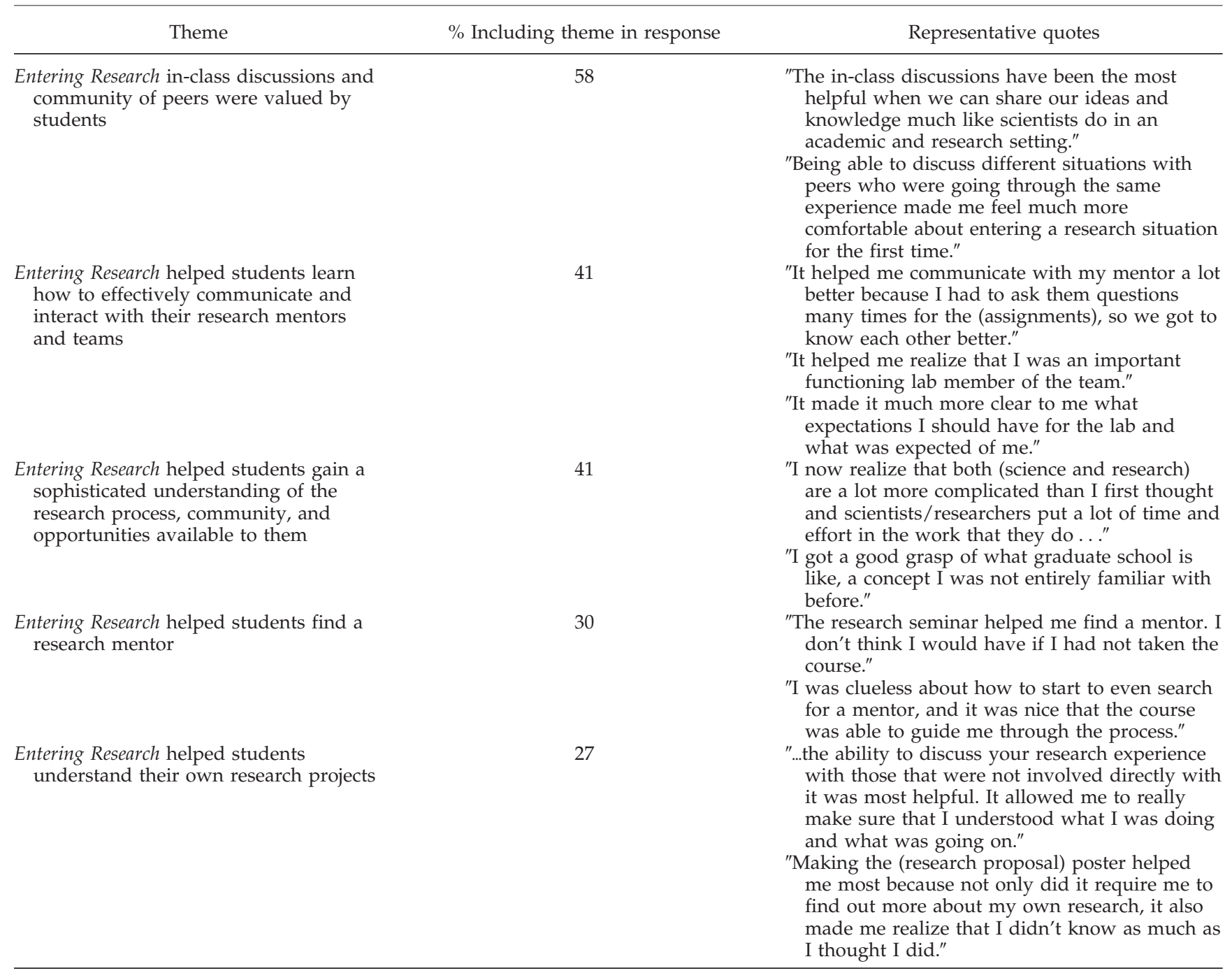

that two of them would have given up and not pursued a lab position if it were not for (this course). Both are now continuing on this semester in the same lab and enjoying their experience. That in itself is SUCCESS!!."

The facilitators also found the course materials valuable (Branchaw et al., 2010). Seventy-one percent identified the case studies and readings as valuable. Seventy-eight percent found the assignments of great value. Finally, 93\% indicated that the in-class discussions were valuable. When asked how facilitating the first semester of the Entering Research course impacted their own mentoring philosophy, participants responded with answers such as the following:

"I had not thought about how [undergraduates] approach faculty for a position in a lab. Much of their frustration about not getting into labs is due to poor application strategies. This is something I now try to pass on to the students I advise. I had not realized they needed so much advice and help in this area before facilitating this class."

\section{DISCUSSION AND IMPLICATIONS}

Here, we describe the development, implementation, and study of a new course, Entering Research, aimed at helping undergraduates better navigate the challenges of beginning research. We demonstrate that student participants find value in Entering Research and report that the course helps them in many ways including finding a mentor, understanding their place in a research community, and connecting their research to their course work in the biological and physical sciences. We demonstrate that students who participate in mentored research have significant gains in their skills, knowledge, and confidence. As noted, such self-reported gains were expected by virtue of the independent research experience. Therefore, we compared their gains to a similar group of introductory biology students who participated in a semester-long independent research experience, but who were not enrolled in the course, to determine 


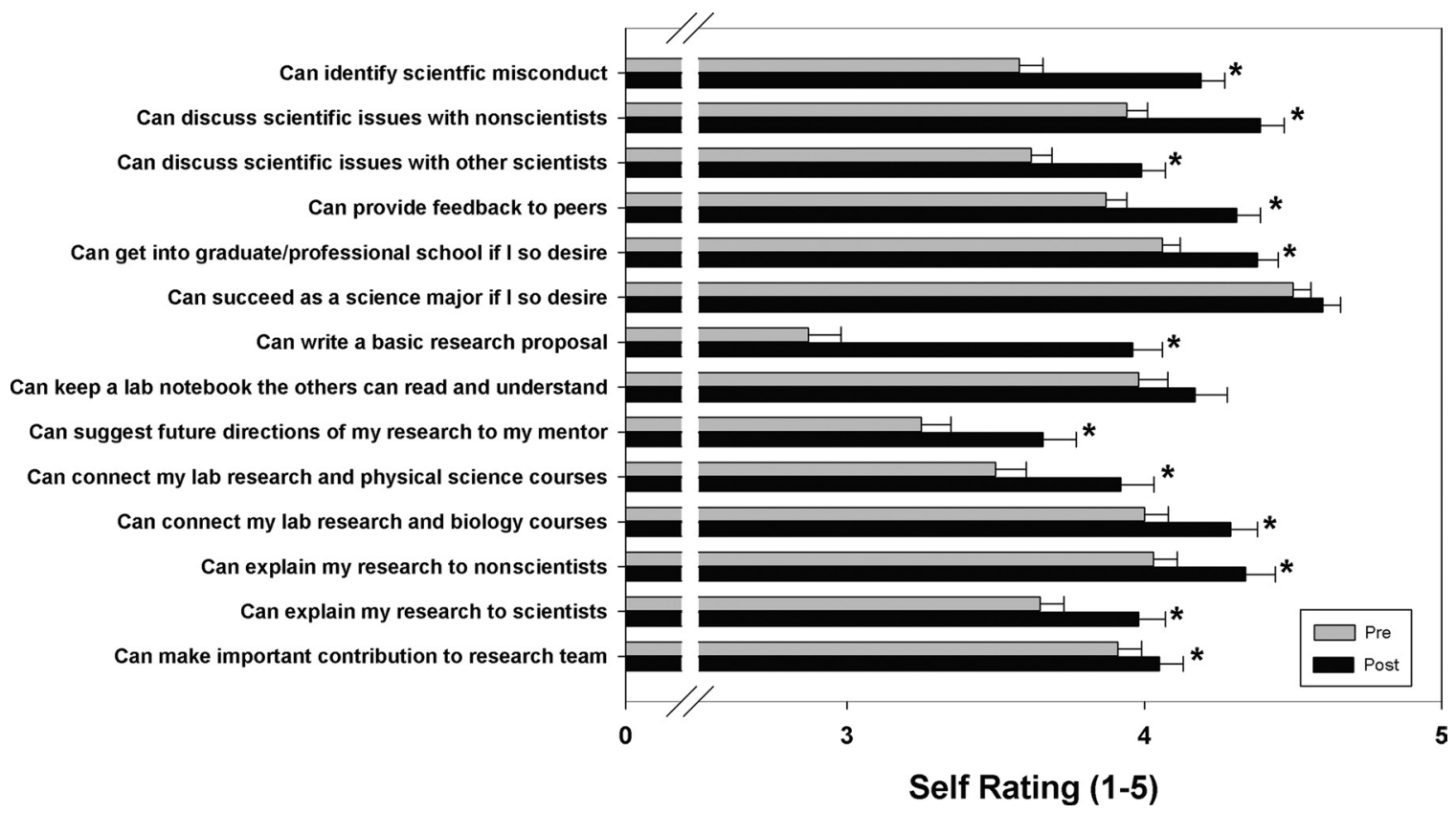

Figure 5. Student self-assessment of confidence as a researcher. Averages of pre- and postsurvey results for each confidence question are presented. Each bar represents the mean and standard error of survey responses from students who took the first semester of Entering Research $(2006-08 ; \mathrm{n}=64)$. Students were asked to report their confidence as a researcher on a scale of 1 through 5 ( $1=$ None; $2=$ Not Very; $3=$ Moderate; $4=$ High; $5=$ Very High). An asterisk indicates a significant difference at $p<0.01$.

whether the gains could be attributed to the course. We found that eight of the self-assessments in a postsurvey were rated significantly higher by the Entering Research students, compared with the comparison group of students (Figure 8).

\section{Benefits of the Entering Research Course}

Within the knowledge category, students in the first semester of the Entering Research course reported higher confidence, compared with the introductory biology students, in making connections between their research experience and their biology or physical sciences classroom experiences. These data are aligned with qualitative research that identified increases in the relevance of course work (Hunter et al., 2007) as well as increased satisfaction in drawing connections between the classroom and laboratory research as selfreported benefits of the undergraduate research experience (Baum et al., 2006). Although students in the introductory biology course also engaged in undergraduate research, the informal discussion-based format of the Entering Research course may explain this difference between groups. In the Entering Research course, students frequently discussed courses they had in common, and the facilitators commented on how those courses related to their students' research projects. These discussions helped establish a community that transcended the students' individual research projects and built broader connections across disciplinary boundaries. Moreover, these informal discussions were coupled with formal discussions of their research projects, further reinforcing shared meaning between classroom learning and research lab learning within a community of practice (Bockarie,
2002). Collectively, these enhanced connections may explain why undergraduate research students who do not participate in a supporting course (e.g., Entering Research) valued their research experience over their course work (Ward et al., 2005), and reported disconnection between their classroom and research learning experiences (Gafney, 2005). Thus, the gains in connectivity between research learning and classroom learning reported here suggest a valuable consequence of including courses such as the Entering Research course into undergraduate research programs, because it provides the opportunity to discuss research in small, safe, and facilitated peer groups.

Students enrolled in the Entering Research course reported higher skill levels in developing a research project, conducting a research project, and analyzing data relative to students in the introductory biology course. Although these are certainly skills encouraged in both courses, we speculate that the higher gains reported by the Entering Research students may be attributed to frequent peer review and informal presentations of research progress required in this course. In addition, multiple opportunities for feedback, from idea to testable hypothesis generation to proposal construction, are also built into the Entering Research course. This finding concurs with other studies examining the benefits of structured undergraduate research programs (Baum et al., 2006). In particular, it aligns with previous work showing that alumni who engaged in research as part of an organized program (e.g., presented ongoing work, wrote research proposals, and made oral presentations) reported a significantly higher ability to carry 


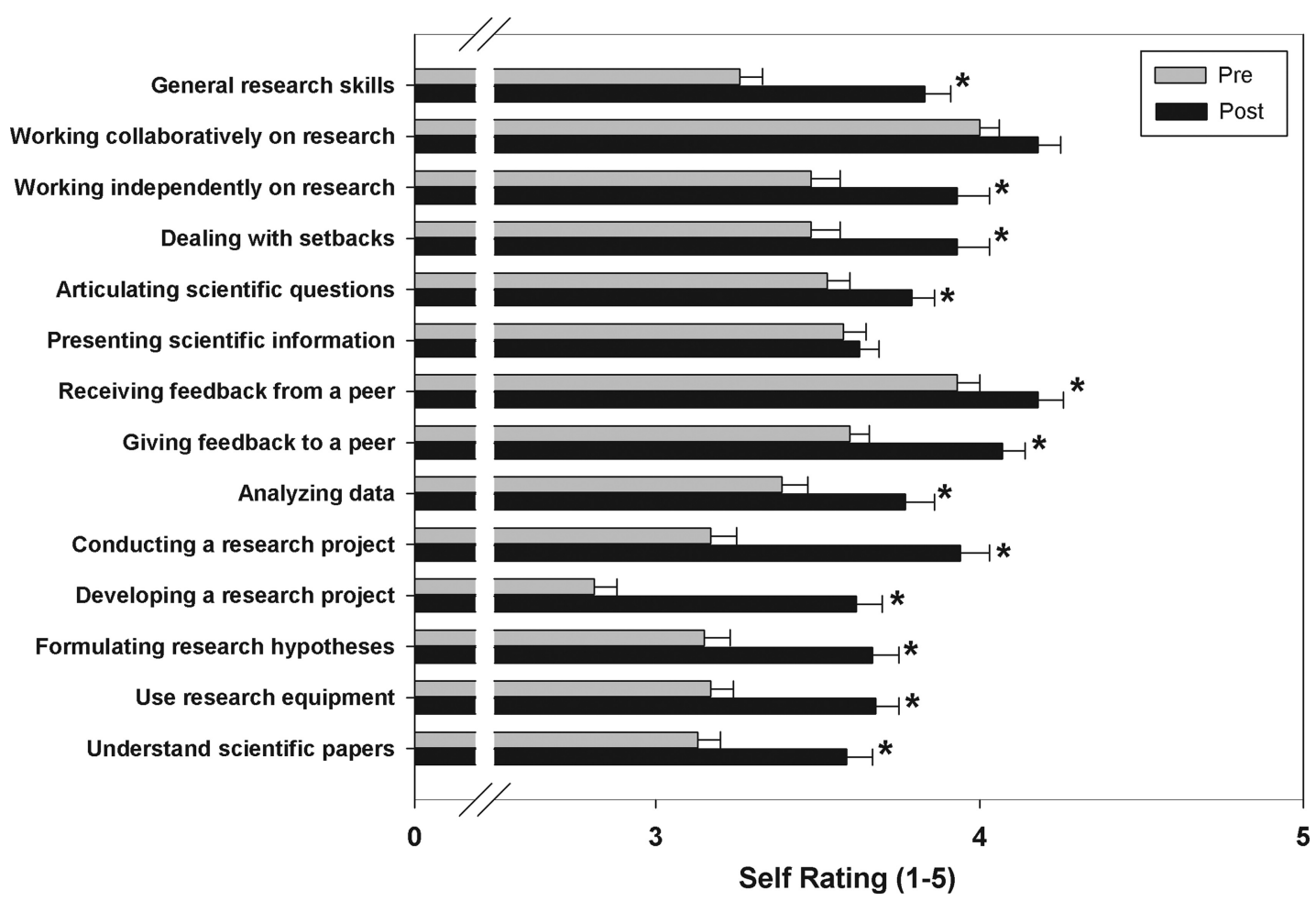

Figure 6. Student self-assessment of skill as a researcher. Averages of pre- and postsurvey results for each skill question are presented. Each bar represents the mean and standard error of survey responses from students who took the first semester of Entering Research (2006-08; $\mathrm{n}=64)$. Students were asked to report their skill as a researcher on a scale of 1 through $5(1=$ None; $2=$ Not Very; $3=$ Moderate; $4=$ High; $5=$ Very High). An asterisk indicates a significant difference at $p<0.01$.

out research than alumni who participated in research on their own, outside the context of a structured undergraduate research program (Bauer and Bennett, 2003). This supports our hypothesis, that programs or courses such as Entering Research can augment the undergraduate research experience and enhance skills and abilities.

Two knowledge questions showed significant differences between the Entering Research course participants and introductory biology students, i.e., what graduate school is like and the career paths of science faculty. We attribute these results to the contact and guided conversations (assignments) that the Entering Research students had with their faculty and staff facilitators, all of whom were current or formerly active researchers with doctorate degrees. In addition, one of the early assignments required students to interview their research mentor and write a biography in an effort to build a stronger mentor-mentee relationship. We propose that the Entering Research assignments like this, which ensured frequent contact between students and research mentors, enhanced the students' ability to understand the careers of graduate students and faculty, and will probably impact their decision to pursue a research career. Although it is too early to assess the impact of the Entering Research course on student career decisions, planned longitudinal studies will enhance our understanding of the long-term impact of enhancing the undergraduate research experience.

\section{Undergraduate Research Experience at a Large Research University}

As mentioned, the benefits of undergraduate research experiences are many and have been widely documented across many institutions of higher learning, as many as 41 in one particular study (Lapatto, 2004). These educational gains extend across gender and ethnicity and include increases in research skills and preparation for postgraduate education (Kardash, 2000; Hathaway et al., 2002; Bauer and Bennett, 2003; Seymour et al., 2004; Hunter et al., 2007; Lopatto, 2007; Russell et al., 2007). The results of this study add to this body of research, as we show a supplemental course that supports the undergraduate research experience further increased gains in skills, confidence, and knowledge. Moreover, previous studies largely focused on upperclassmen or alumni who participated in summer research at a range of institutions, many of which were liberal arts colleges. In contrast, the study described here is novel in its strategic focus on early career students engaged in academic year-long research at a research extensive university.

Although improving, a significant challenge remains for early undergraduate students at large, research extensive institutions in finding a research mentor and getting established in a research lab (Baum et al., 2006), which the first semester of the Entering Research course was designed to support. Importantly, almost a third of the students enrolled in the Entering Research course indicated that they would not have pursued independent research without 


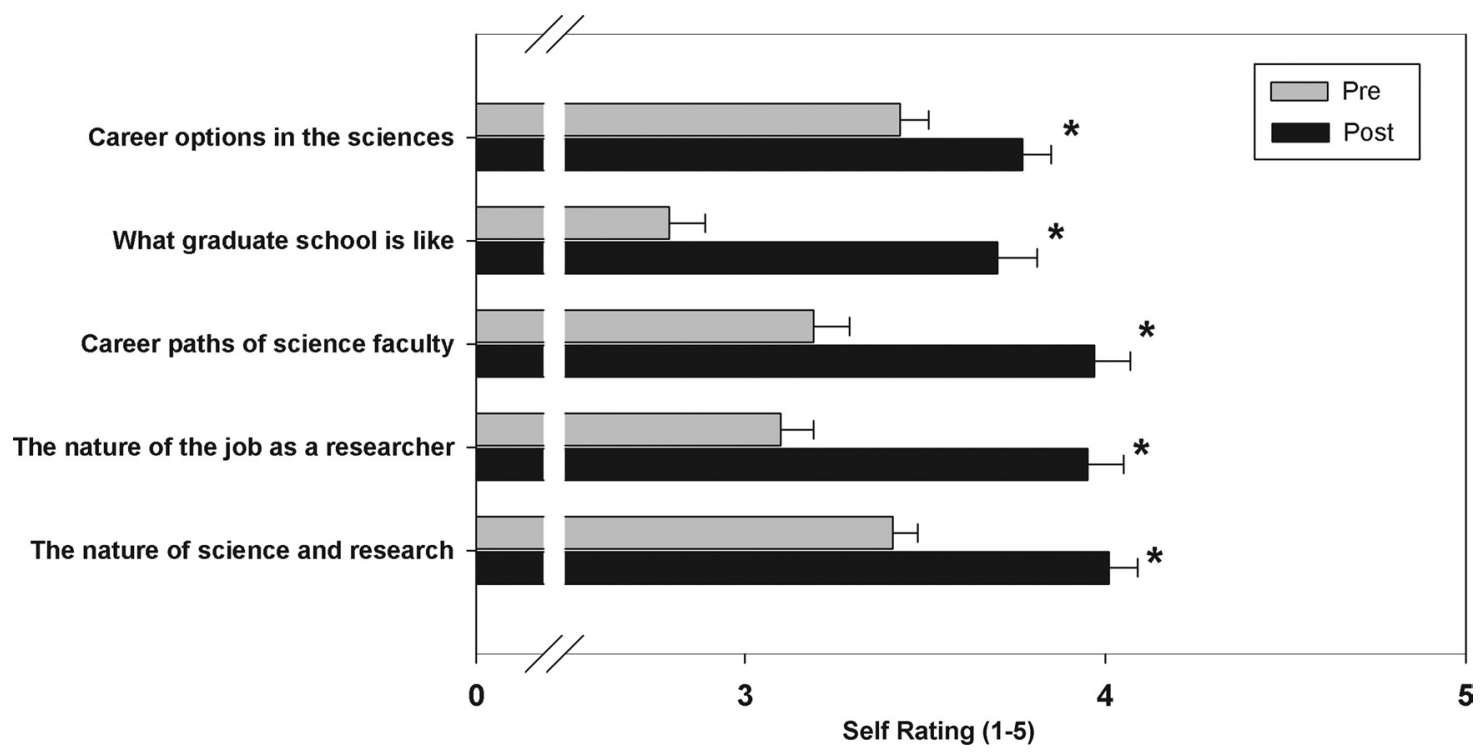

Figure 7. Student self-assessment of knowledge as a researcher. Averages of pre- and postsurvey results for each knowledge question are presented. Each bar represents the mean and standard error of survey responses from students who took the first semester of Entering Research $(2006-08 ; \mathrm{n}=64)$. Students were asked to report their knowledge as a researcher on a scale of 1 through $5(1=$ None; $2=$ Not Very; $3=$ Moderate; $4=$ High; $5=$ Very High). An asterisk indicates a significant difference at $p<0.01$.

the support of the course. This result is particularly relevant as institutions attempt to find ways to increase and retain students interested in science careers. Indeed, many studies have shown mentored research experience as essential to the recruitment and retention of students in science (Nagda et al., 1998; Hathaway et al., 2002; Baum et al., 2006), especially underrepresented minorities and women who may not have the confidence or experience to navigate the system. For example, a recent study examin- ing the effects of a supplemental support program for women in the STEM disciplines found similar results to the results reported here (Kahveci et al., 2006). Specifically, the attitudes, performance, and retention of undergraduate women participating in the support and mentoring program were compared with similar students not enrolled in this additional program. Despite no significant difference between the groups in academic potential, views, and interest to pursue science, a greater number of

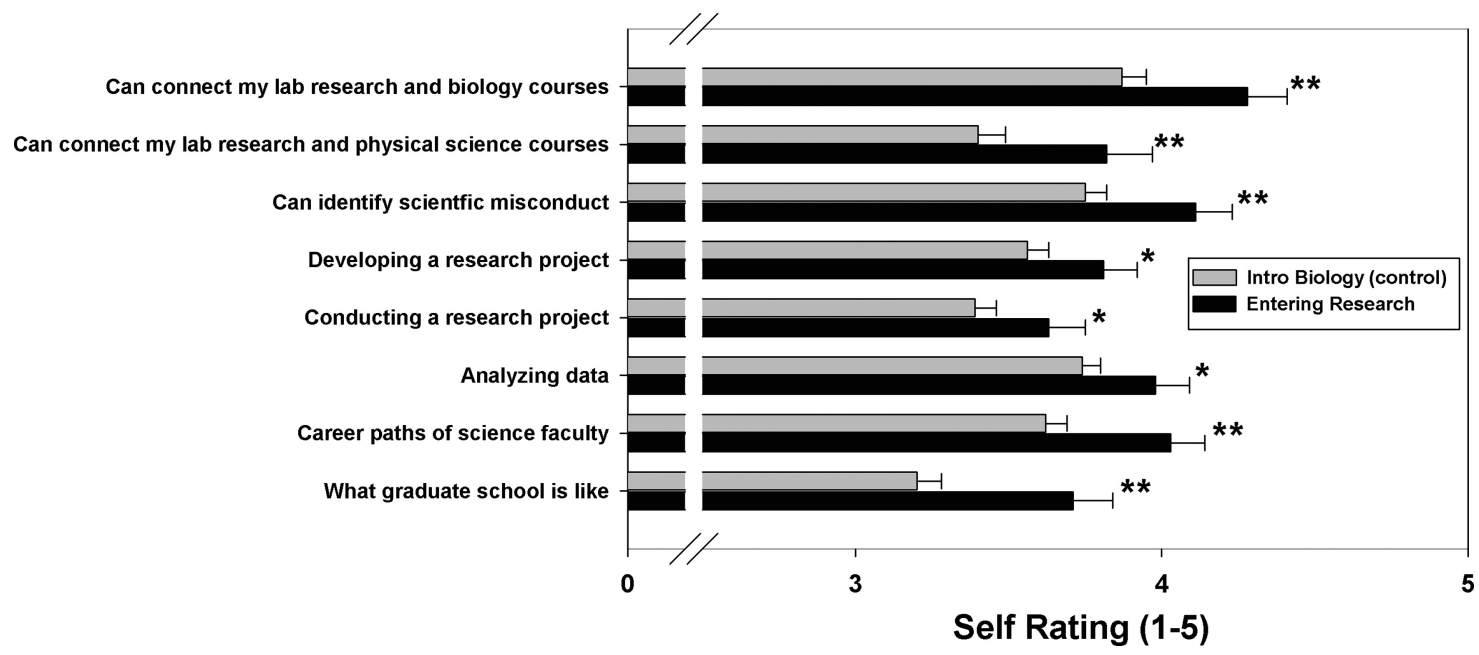

Figure 8. Areas of significant difference between Entering Research and a comparison group of students. Averages of postsurvey results are presented. Each bar represents the mean and standard error of survey responses from students who took the first semester of Entering Research (2006-08) ( $\mathrm{n}=64)$ and from students who did an independent research experience as part of introductory biology (n = 144). Students were asked to report their confidence, skill, or knowledge as a researcher on a scale of 1 through $5(1=$ None; $2=$ Not Very; $3=$ Moderate; 4 = High; 5 = Very High). A single asterisk indicates a significant difference at $\mathrm{p}<0.05$; a double asterisk indicates a significant difference at $p<0.01$. All other areas of confidence, skills, and knowledge were not significantly different within our data set. 
women in the support program found research experiences and decided to remain in a STEM discipline after their first year in college. Thus, it seems that a support structure, such as the Entering Research course is critical to the success of undergraduates pursuing STEM disciplines and research activities that enhance their experience.

\section{Mentor-Mentee Relationship}

Although undergraduate research experiences can offer great benefits to all engaged, it is also true that they can be very time-consuming and resource intensive for the mentors. In addition, the large numbers of undergraduate students at public research universities like UW-Madison increases the difficulty to recruit sufficient numbers of faculty mentors (Wood, 2003; Desai et al., 2008). The Entering Research course was developed with these challenges in mind. This course alleviates some of the responsibility of mentoring by supporting and empowering students to effectively work with their mentors, by leveraging the large numbers of prefaculty (graduate student and postdoctoral fellow) mentors available at these types of institutions, and by aligning with an existing training program for undergraduate mentors (Pfund et al., 2006).

Using graduate students and postdoctoral fellows as mentors of undergraduate research students can be a win-win situation if done properly. These mentors are often able to increase face-to-face time with undergraduate researchers, may be better able to relate to undergraduate students, and can benefit from the practice of mentoring (Dolan and Johnson, 2009). Moreover, these mentors can serve as liaisons between undergraduate research projects and principal investigators, because professors running large research programs often have limited time to spend with each student. Thus, to support these mentors, the first semester of the Entering Research course was intentionally aligned with the Wisconsin Mentoring Seminar, Entering Mentoring (Handelsman et al., 2005; Pfund et al., 2006) for graduate students, postdoctoral fellows, and faculty. Data show that strong mentor-mentee relationships are a cornerstone of successful undergraduate research experiences (Shellito et al., 2001; McGee and Keller, 2007). Both the Entering Research and Entering Mentoring courses include activities that build these relationships and provide both peer groups with opportunities to discuss challenges that arise in these relationships. Because these programs work in concert to enhance the close working relationships between mentors and students as they pursue scientific research together, we propose that coupling these seminars will maximize the benefits of the experience for both mentors and students, and we are currently testing this hypothesis.

\section{Value of Learning Communities to Undergraduate Research Experiences}

In addition to helping students establish positive relationships with their mentors, the Entering Research course creates a learning community where beginning researchers can safely share their experiences and begin to identify themselves as members of the research community. This longstated goal of undergraduate research programs (Foertsch et al., 1997; Nagda et al., 1998) was met, because our results showed students rating this aspect of the course as very helpful. This sense of community is especially important for those who are new to the culture of research, such as firstgeneration college students, in large public universities such as the UW-Madison. As large public universities seek to improve their graduation rates (Bowen et al., 2009), finding ways to help all students succeed is critical. Bauer and Bennett (2003) show that alumni who participated in undergraduate research rated their educational experience more highly than those who did not. They also rated their ability to: speak effectively, act as leaders, analyze literature critically, possess clear career goals and develop intellectual curiosity significantly higher than those without a research experience. If a goal of higher education is to instill a broad range of cognitive skills, as well as students' satisfaction with their educational experience, then providing support for students, especially those from underrepresented groups, to navigate their undergraduate research experience is critical.

Entering Research represents one approach to supporting and enhancing the undergraduate research experience. Future work is aimed at studying the impact of the second semester of the Entering Research course, which helps students complete their research, present their findings in a public venue, and write a minigrant proposing future work. Efforts are also being made to implement and evaluate the course at a variety of institutions and with diverse populations of students.

\section{ACKNOWLEDGMENTS}

We thank the Introductory Biology 152 staff for assistance in data collection and Sumana Abeyratne for statistical assistance. We thank all of the facilitators of the Entering Research course. We thank Jo Handelsman for early conceptual contributions, the UW-Madison Center for Biology Education for the intellectual support and freedom allowed their staff to develop the course, and the UWMadison Institute for Cross-College Biology Education for the administrative support needed to pilot the course. This research was funded by National Science Foundation grant 0552806 (to J. B. and C. P.), a Howard Hughes Medical Institute Professors grant (to J. Handelsman), and the UW-Madison Institute for Cross-College Biology Education.

\section{REFERENCES}

American Society for Biochemistry and Molecular Biology (2008). Biochemistry/Molecular Biology and Liberal Education: A Report to the Teagle Foundation. Bethesda, MD.

Bauer, K. W., and Bennett, J. S. (2003). Alumni perceptions used to assess undergraduate research experience. J. High. Educ. 74, 210 230.

Baum, M. M., Krider, E. S., and Moss, J. A. (2006). Accessible research experiences: a new paradigm for in-lab chemical education. J. Chem. Educ. 83, 1784-1786.

Bockarie, A. (2002). The potential of Vygotsky's contributions to understanding of cognitive apprenticeship as a process of development in adult vocational and technical education. J. Career Technol. Educ. 19, 47-66.

Bowen, W. G., Chingos, M. M., and McPherson, M. S. (2009). Crossing the Finish Line: Completing College at America's Public Universities. Princeton, NJ: Princeton University Press. 
Boyd, M. K., and Wesemann, J. L.(eds.) (2009). Broadening Participation in Undergraduate Research: Fostering Excellence and Enhancing the Impact. Washington, DC: Council on Undergraduate Research.

Boyer Commission on Educating Undergraduates in the Research University (1998). Reinventing Undergraduate Education: A Blueprint for America's Research Universities, Menlo Park, CA: Carnegie Foundation for the Advancement of Teaching.

Branchaw, J. L., Rediske, R., and Pfund, C. (2010). Entering Research: Workshops for Students Beginning Research in ScienceFacilitator's Manual, New York: W. H. Freeman and Co.

Brown, B. A. (2006). "It isn't no slang that can be said about this stuff": Language, identity, and appropriating science discourse. J. Res. Sci. Teach. 43, 96-126.

Desai, K. V., Gatson, S. N., Stiles, T. W., Stewart, R. H., Laine, G. A., and Quick, C. M. (2008). Integrating research and education at research-extensive universities with research-intensive communities. Adv. Physiol. Educ. 32, 136-141.

Dolan, E., and Johnson, D. (2009). Towards a holistic view of undergraduate research experiences: an exploratory study of impact on graduate/ postdoctoral mentors. J. Sci. Educ. Technol. http:// dx.doi.org/10.1007/s10956-009-9165-3.

Foertsch, J. A., Alexander, B. B., and Penberthy, D. L. (1997). Evaluation of the UW-Madison's summer undergraduate research programs: Final report. Madison, WI: University of Wisconsin-Madison, LEAD Center.

Fraenkel, J. R., and Wallen, N. E. (2003). How to Design and Evaluate Research in Education, 5th ed. New York: McGraw-Hill.

Gafney, L. (2005). The role of the research mentor/teacher: student and faculty views. J. Coll. Sci. Teach. 34, 52-57.

Handelsman, J., Pfund, C., Miller Lauffer, S., and Maidl Pribbenow, C. (2005). Entering Mentoring: A Seminar to Train a New Generation of Scientists. Madison, WI: University of Wisconsin Press.

Hathaway, R. S., Nagda, B. A., Gregerman, S. R. (2002). The relationship of undergraduate research participation to graduate and professional education pursuit: an empirical study. J. Coll. Stud. Dev. 43, 614-663.

Hsieh, H.-F., and Shannon, S. (2005). Three approaches to qualitative content analysis. Qual. Health Res. 15, 1277-1288.

Hunter, A.-B., Laursen, S. L., Seymour, E. (2007). Becoming a scientist: the role of undergraduate research in students' cognitive, personal, and professional development. Sci. Educ. 91, 36-74.
Kahveci, A., Southerland, S. A., and Gilmer, P. J. (2006). Retaining undergraduate women in science, mathematics, and engineering. J. Coll. Sci. Teach. 36, 34-38.

Kardash, C. M. (2000). Evaluation of an undergraduate research experience: perceptions of undergraduate interns and their faculty mentors. J. Educ. Psychol. 92, 191-201.

Lopatto, D. (2004). Survey of undergraduate research experiences (SURE): first findings. Cell Biol. Educ. 3, 270-277.

Lopatto, D. (2007). Undergraduate research experiences support science career decisions and active learning. CBE Life Sci. Educ. 6, 297-306.

McGee, R., and Keller, J. L. (2007). Identifying future scientists: predicting persistence into research training. CBE Life Sci. Educ. 6, 316-331.

Nagda, B. A., Gregerman, S. R., Jonides, J., Hippel, W. V., and Lerner, J. S. (1998). Undergraduate student faculty research partnerships affect student retention. Rev. High. Educ. 22, 55-72.

National Research Council (2003). Bio 2010, Transforming Undergraduate Education for Future Research Biologists. Washington DC: National Academies Press.

Pfund, C., Maidl Pribbenow, C., Branchaw, J., Miller Lauffer, S., and Handelsman, J. (2006). The merits of training mentors. Science 311, 473-474.

Russell, S. H., Hancock, M. P., McCullough, J. (2007). The pipeline: benefits of undergraduate research experiences. Science 316, $548-$ 549

Seymour, E. L., Hunter, A.-B., Laursen, S., and DeAntoni, T. (2004). Establishing the benefits of research experiences for undergraduates: first findings from a three-year study. Sci. Educ 88, 493-594.

Shellito, C., Shea, K., Weissmann, G., Mueller-Solger, A., and Davis, W. (2001). Successful mentoring of undergraduate researchers: tips for creating positive student research experiences. J. Coll. Sci. Teach. $30,460-465$

Villarejo, M., Barlow, A.E.J., Kogan, D., Veazey, B. D., and Sweeney, J. K. (2008). Encouraging minority undergraduates to choose science careers: career paths survey results. CBE Life Sci. Educ. 7, 394-409.

Ward, C., Bauer, K., and Bennet, J. (2005). Content analysis of undergraduate student research evaluations. www.udel.edu/ RAIRE/Content.pdf/ (accessed 10 September 2009).

Wood, W. B. (2003). Inquiry-based undergraduate teaching in the life sciences at large research universities: a perspective on the Boyer Commission Report. Cell Biol. Educ. 2, 112-116. 